\title{
Experimental and Theoretical Study of the Products from the Spontaneous Dimerization of DL- and D-Glyceraldehyde
}

\author{
Federico García-Jiménez ${ }^{*, a}$, Ofelia Collera Zúñiga ${ }^{a}$, Yolanda Castells García ${ }^{b}$, Julio Cárdenas ${ }^{c}$ and \\ Gabriel Cuevas*,a
}

\author{
${ }^{a}$ Instituto de Química, Universidad Nacional Autónoma de México, Circuito Exterior, Ciudad Universitaria 04510, \\ Coyoacán, México D.F., México \\ ${ }^{b}$ Escuela Nacional Preparatoria, Universidad Nacional Autónoma de México, Plantel Antonio Caso, \\ Coyoacán, 04500 México D.F., México
}

${ }^{c}$ Escuela de Ciencias Químicas, Universidad La Salle, Benjamín Franklin 47, Hipódromo Condesa, 06140 México D.F., México

\begin{abstract}
A estrutura molecular predominante para o DL e para o D-gliceraldeído foi estudada utilizando espectroscopia de infravermelho e de ressonância magnética nuclear. As duas técnicas mostraram que, a temperatura ambiente, estes compostos apresentam apenas uma pequena porcentagem da forma aldeído. Estes estudos mostraram que a forma aldeído para o D-(+)-gliceraldeido coexiste, como componente em pequena proporção, com uma mistura complexa de diastereosômeros do 2,5di-hidroxi-3,6-di-hidroximetil-1,4-dioxano, enquanto a mistura racêmica é constituída por dois compostos principais. A estabilidade dos diasteroisômeros é controlada pela formação de ligações de hidrogênio intramoleculares em decorrência do efeito anomérico, que define a posição favorável para o grupo hidroxila. As interações anoméricas endo e exo são originadas pela interação estereoeletrônica $n_{\mathrm{O}} \rightarrow \sigma^{*}{ }_{\mathrm{C}-\mathrm{O}}$. Utilizando cálculos teóricos em nível B3LYP/6-31G(d,p) foi possível estabelecer a estrutura dos confôrmeros favorecidos.
\end{abstract}

The predominant molecular structure of DL and D-glyceraldehyde has been studied with infrared and nuclear magnetic resonance spectroscopies. Both techniques show that these compounds at room temperature have a minor percentage of the aldehydic form. These studies showed that D-(+)glyceraldehyde coexists in a minor proportion as a component of a complex mixture of diasteroisomers of the 2,5-dihydroxy-3,6-dihydroxymethyl-1,4-dioxane, while the racemic mixture is made of two main compounds. The stability of the isolated diasteroisomers is controlled by the formation of intramolecular hydrogen bonds that are formed under the control of the anomeric effect which defines the favored position for the hydroxyl group. The endo and exo-anomeric interactions have their origin in the stereoelectronic interaction $n_{\mathrm{O}} \rightarrow \sigma^{*}{ }_{\mathrm{c}-\mathrm{O}}$. Using theoretical calculations at B3LYP/ 6-31G(d,p) level, it was possible to establish the structure of the favored conformers.

Keywords: DL-glyceraldehyde, D-glyceraldehyde, 1,4-dioxanes, nuclear magnetic resonance, density functional calculations, stereoelectronic effects, anomeric effect, hydrogen bond, weak interactions

\section{Introduction}

The so-called weak interactions are fundamental in the development of emerging areas of Chemistry such as Supramolecular Chemistry and Crystal Engineering. These interactions are also of great importance in the molecular recognition that controls biological functions, so it is paramount to understand their origin, establish their magnitude and the factors that modify them. In this study,

*e-mail: fedgar@servidor.unam.mx,gecgb@servidor.unam.mx we selected for the analysis glyceraldehyde, a molecule where several types of these interactions coexist and affect molecular energy.

D-glyceraldehyde is without any doubt one of the most important compounds in the fields of chemistry, biochemistry and biology. It is the first carbohydrate produced by most plants in photosynthesis as 3phosphoglycerate. ${ }^{1}$ Most chemists and biochemists are familiar with the D- and L- molecular structures of glyceraldehydes which appear in Chemistry and 
Biochemistry textbooks, ${ }^{2}$ and is the reference to establish the absolute stereochemistry of all chemical compounds with which it is directly or indirectly correlated. ${ }^{3}$ However if the infrared technique is used to evaluate a sample of commercial glyceraldehyde, it is impossible to find a strong infrared band for an aldehyde function as the name implies. In the case of DL-glyceraldehyde the possibility of a polymerization by hemiacetalization was already mentioned by Wohl ${ }^{4}$ in the first reported synthesis of this compound. Later Wohl and Neuberg ${ }^{5}$ proposed the formation of cyclic dimeric hemiacetal for DLglyceraldehyde. In $\mathrm{D}_{2} \mathrm{O}$ solution of DL-glyceraldehyde it has been found that the intensity of the band associated with the carbonyl group increases as the temperature increases. ${ }^{6}$ The percentage of free D-glyceraldehyde has been estimated as $9.8 \%$ and $4.4 \%$ using infrared (at 1729 $\left.\mathrm{cm}^{-1}\right)$ and the ultraviolet $(273 \mathrm{~nm})$ confirm the presence of a carbonyl group in low concentration. ${ }^{7}$ Purification by means of activated carbon does not modify these results. DL-glyceraldehyde-3-phosphate shows similar results. The trimethylsilyl derivative of DL-glyceraldehyde has also been shown to correspond to the dimeric cyclic hemicetal using NMR spectroscopy. ${ }^{8}$

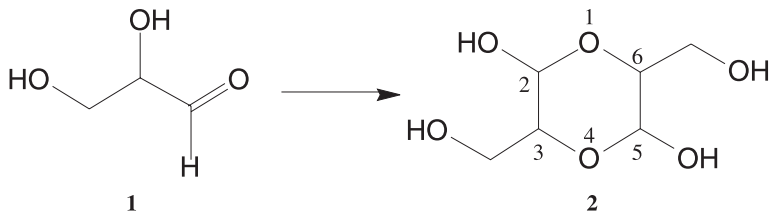

Figure 1. Dimerization of glyceraldehyde.

There is also an increase of the enolic form of the aldehyde which may lead to some transformation into hydroxyacetone when the temperature increases. Since this process is reversible it may also lead to racemization. ${ }^{4}$ In the case of dihydroxyacetone there is also formation of cyclic dimers but the proportion of the dimeric form is low. ${ }^{7}$

\section{Results}

DL-glyceraldehyde and D-glyceraldehyde were studied using Infrared spectroscopy together with ${ }^{13} \mathrm{C}$ and ${ }^{1} \mathrm{H}$ nuclear magnetic resonance. In the case of commercial DL-glyceraldehyde $1 \%$ or less of the free carbonyl band according to the intensity in the solid state was found. This is in agreement with the information from both ${ }^{13} \mathrm{C}$ and ${ }^{1} \mathrm{H}$ nuclear magnetic resonance. In contrast D-glyceraldehyde, shows $10 \pm 0.2 \%$ of the free carbonyl as determined from the intensity of the carbonyl band at
$1731 \mathrm{~cm}^{-1}$ we also observed an enol band at $1643 \mathrm{~cm}^{-1}$. This information is in agreement with the information from ${ }^{13} \mathrm{C}$ and ${ }^{1} \mathrm{H}$ nuclear magnetic resonance (in ${ }^{1} \mathrm{H}$ resonance there is a doublet centered at 9.61 ppm for an aldehyde proton and in ${ }^{13} \mathrm{C}$ resonance a signal appear at $204.6 \mathrm{ppm}$ for the carbonyl function).

Determination of the hemiacetal dimeric structure of $D L$ and D-glyceraldehyde

First the solid DL-glyceraldehyde was studied. The ${ }^{13} \mathrm{C}$ NMR of this compound is rather simple, it shows only three main signals at $92.4 \mathrm{ppm}$ for 2-C(2,5) (Figure 1). A signal at 78.9 ppm for carbon $\mathrm{C}(3,6)$ in a dioxane ring and finally a signal at $60.5 \mathrm{ppm}$ for a hydroxymethylene moiety. The system must have high symmetry since it shows only three signals for six carbon atoms. The ${ }^{1} \mathrm{H} N \mathrm{NR}$ of this compound in DMSO- $d_{6}$ is also relatively simple. It shows only one doublet (6.72 and $6.70 \mathrm{ppm}$ ) for two protons at the oxygen atom of two hydroxyl groups in two dioxane carbons ( $\mathrm{C} 1$ in glyceraldehyde), which in turn have one proton each at $4.5 \mathrm{ppm}$ showing also couplings with two symmetrically placed protons at about $3.2 \mathrm{ppm}$ on the dioxane ring (C2 in glyceraldehyde). The $\mathrm{OH}$ proton in the hydroxymethylene groups gives a triplet and is coupled to a gem $\mathrm{AB}$ system of the hydrogens at the hydroxymethylenes which show a multiplet between 3.6 and 3.3, also coupled with the protons at $3.2 \mathrm{ppm}$. Both NMR spectra $\left({ }^{13} \mathrm{C}\right.$ and $\left.{ }^{1} \mathrm{H}\right)$ show slight modification which include the appearance of additional peaks, indicating stability between 20 and $80{ }^{\circ} \mathrm{C}$.

The data above correspond to a highly symmetrical substituted 1,4-dioxane dimeric hemiacetal. The structure includes very strong intramolecular hydrogen bonds since the ${ }^{1} \mathrm{H}$ NMR spectra show only slight modifications between 20 and $80{ }^{\circ} \mathrm{C}$. This structure has specific stereochemistry and during its formation two new asymmetric centers are induced in a natural regio-specific synthesis. Commercial DL-glyceraldehyde is thus not an epimeric mixture, but produces an epimeric hemicetal by spontaneous dimerization.

In the case of the commercial D-glyceraldehyde, the ${ }^{13} \mathrm{C}$ shows a large number of peaks instead of the simple patterns for the DL-glyceraldehyde. One of the peaks is at 204.6 ppm and is assigned to the carbon atom in a carbonyl function of glyceraldehydes. Other 16 peaks are seen even after eliminating small peaks, which may be attributed to free glyceraldehydes hydrates. The large number of peaks may be attributed to different combinations of dimeric stereoisomers and other different conformers and hydrates (see below). The region between 104.5 and 90.2 ppm may 
be assigned to the presence of carbon atoms of hemicetal type and shows 18 signals. This may be assigned to the three main stereoisomers in different conformations. We also have to remember that one of the differences between DL- and D-glyceraldehyde is the level of hydration which in the last case amounts to about $0.17 \mathrm{~mol}$ of water per mol of the aldehyde and in the first case is almost absent. Between 83.5 and $77.5 \mathrm{ppm}$ there are six main signals which correspond to carbon at position 3 and 6 of the dioxane ring ( $\mathrm{C} 2$ of the glyceraldehyde) this agree with three main stereoisomers, this particular atom does not have hydroxyl or hydroxymethylene groups and will not change very much because of differences in hydrogen bonding. Finally, between 73.9 and 59.4 ppm we find 24 peaks which correspond to the hydroxymethylene carbon. This carbon shows the highest possibility of forming different conformations and combinations of hydrogen bonding including those with a molecule of water. The ${ }^{1} \mathrm{H}$ NMR is also very complex showing a signals for an aldehyde group at 9.620 and 9.617 ppm its integration is barely noticeable. Between 6.55 and $6.34 \mathrm{ppm}$ there is a series of doublets corresponding to the $\mathrm{OH}$ group at $\mathrm{C}-2$ and C-4 of a dioxane ring; six of them are most noticeable, further doublets are seen between 6.06 and 5.79 and between 5.61 and $5.41 \mathrm{ppm}$. Between 3.98 and $3.13 \mathrm{ppm}$ there is a complex multiplet signal. The signal appear in the same region as for DL-glyceraldehyde but the pattern is much more complicated because of the presence of many dimeric hemicetal isomers and conformers as well as by the presence of different hydrates.

\section{Computational study}

When the $\mathrm{R}$ enantiomer of glyceraldehyde (1, Figure 1 ) is dimerized, it can lead the ring of 1,4-dioxane through the attack of the hydroxyl group at position 2 to any of the proquiral phases of the carbonyl group perhaps following the path according to by Cram's model. ${ }^{9}$ Four possible stereoisomers of 2,5-dihydroxy-3,6-dihydroxymethyl-1,4dioxane can be generated (2, Figure 1) and are presented in equations 1 to 4 . When the racemic mixture is studied, in other words from the equimolecular mixture of the $\mathrm{R}$ and $\mathrm{S}$ enantiomers, four new additional diasteroisomers can be produced (equations 5 to 8 ) and of course their corresponding enantiomers. In summary, a total of 16 possible diasteroisomers are obtainded, 8 pairs of enantiomers.

Thus, the stereogenic centers at positions 3 and 6 are defined by the original configuration of glyceraldehydes (only series $\mathrm{R}$ will be addressed here) while those at positions 2 and 4 (anomeric positions) are defined when the condensation that originates dioxane takes place. Each one of these diasteroisomers presents two possible conformational arrangements due to the ring inversion of 1,4-dioxane. ${ }^{10}$ Since the chair conformer is known to be the most stable arrangement of 1,4-dioxane, this study will only address this type. In each arrangement, the different type of interactions that affects the molecular stability is investigated.

From previous studies, ${ }^{11}$ it is possible to conclude that the endo and exo-anomeric effect is the factor that influences the stability of 2-methoxy-oxane, thus, these effects should show in the stability of the stereoisomers of interest. Hydrogen bonds are of more importance due to their stabilizing capacity. The hydroxymethyl group can be involved and restrict their degrees of conformational freedom. Four types of hydrogen bonds can be expected; the hydrogen bonds where the $\mathrm{OH}$ group on the anomeric position is the donor and the hydroxymethyl the acceptor (for example equation 1); those where this relationship is inverted (for example, conformers 9 and 13 of equation 4); those where the hydroxyl group is the donor and the annular oxygen is the acceptor (7, equation 4); and finally, those formed by three groups where the anomeric hydroxyl group is both, the donor and the acceptor (10, equation 3 ).

Equations 1 through 4 show four conformational equilibria of four diasteroisomers for compound 2 generated by the dimerization of the $\mathrm{R}$ enantiomer of glyceraldehyde (for all equations total energy is in Hartrees and relative energy in $\mathrm{kcal} / \mathrm{mol}$ ). On equation $12 \mathrm{R}, 5 \mathrm{R}$ dihydroxy-3R,6R-dihydroxymethyl-1,4-dioxane, hereon referred to as RRRR-(2), where the configuration of the stereogenic centers corresponds to the 2,3,5 and 6 positions, respectively.

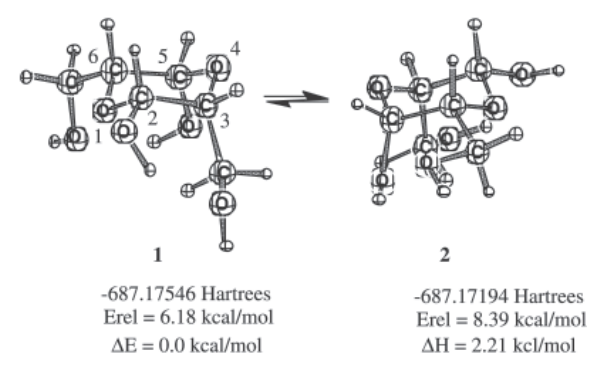

At B3LYP/6-31G(d,p) level, conformer $\mathbf{1}$ is $2.21 \mathrm{kcal} /$ mol more stable than conformer 2 . In conformer $\mathbf{1}$ the hydroxyl group at position 2 participates as a donor of hydrogen bond to the hydroxymethyl group at position 3 . Since it occupies the equatorial position, it cannot be favored by the endo-anomeric interaction, ${ }^{12}$ but it can be by the exo-anomeric, even when the hydrogen atom does 
not adopt the optimal position from the stereoelectronic point of view in order to favor the formation of an hydrogen bond. In contrast, the hydroxyl group at position 5 can benefit of the endo-anomeric interaction but not by the exo-anomeric one because the hydrogen atom occupies that position to form the hydrogen bond with the hydroxymethyl group. In conformer $\mathbf{2}$ the hydroxyl group at position 2 is benefited only by the endo-anomeric ( $n_{\text {Oendo }}$ $\left.\rightarrow \sigma^{*}{ }_{\text {C-O }}\right)$ interaction while the hydroxyl group at position 5 is only benefited by the exo-anomeric $\left(n_{\text {Oexo }} \rightarrow \sigma^{*}{ }_{\text {C-O }}\right.$ ) interaction. ${ }^{12,13}$ This sets-up a certain balance in terms of the stereoelectronic interactions among compounds $\mathbf{1}$ and 2. However, the hydroxyl at position 5 is now the acceptor in the formation of the hydrogen bond and not the donor like the hydroxyl at position 2. This allows for the establishment of the most stabilizing contribution of the hydrogen bonds that is produced when the atom that participates in a stereoelectronic interaction is also the donor in the hydrogen bond.

On equation 2 two conformers of the compound of configuration RRSR-2 are presented. On conformer 3 the hydroxyl groups are equatorial, so they are not benefited by the $n_{\text {Oendo }} \rightarrow \sigma^{*}{ }_{\text {C-O }}$ interaction and the antiperiplanar disposition of the $\mathrm{O}-\mathrm{H}$ bond in relation to the $\mathrm{C} 5-\mathrm{O}$ bond may point out that the $n_{\text {Oexo }} \rightarrow \sigma^{*}{ }_{\text {C-O }}$ interaction cannot occur, but in some manner is substituted by the $\sigma_{\mathrm{H}-\mathrm{O}} \rightarrow$ $\sigma_{\text {C-O }}^{*}$ interaction. This disposition of less stabilizing capability is due to the formation of an hydrogen bond where this group is the donor to the hydroxylmethyl group at position 6. The hydroxyl group at position 2 is also a donor of the hydrogen bond, that persists in conformer 4 where the group is benefited by the $n_{\text {Oendo }} \rightarrow \sigma^{*}{ }_{\text {C-O }}$ interaction and forms a second hydrogen bond as acceptor of the hydroxymethyl group at position 6. On the other hand, the hydroxyl group at position 5 is benefited by the $n_{\text {Oendo }} \rightarrow \sigma^{*}{ }_{\text {C-O }}$ an $n_{\text {Oexo }} \rightarrow \sigma_{\text {C-O }}^{*}$ interactions. Conformer 4 that combines two hydrogen bonds where the hydroxyl group is the donor and acceptor of the hydrogen bond and the hydroxyl groups in axial position that are favored by the anomeric effect, is $3.18 \mathrm{kcal} / \mathrm{mol}$ more stable than the conformer that presents two independent hydrogen bonds and lacks the stabilizing benefit of the anomeric effect.

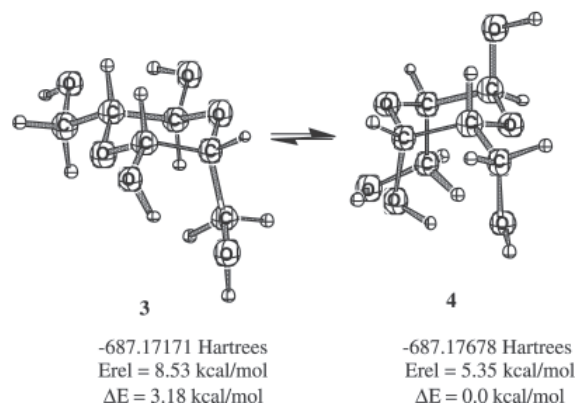

Equation 3 presents a pair of conformers of the diasteroisomer with SRSR configuration. On conformer 5, the trans-diaxial nature of the groups at positions 2 and 3 block the mutual formation of hydrogen bonds. Because the hydroxyl at position 5 is equatorial it cannot form a bond like the one formed in conformer $\mathbf{4}$, but the formation of a hydrogen bond with the hydroxymethyl group on position 6 is favored. The hydroxyl group at position 2 is benefited from the endo and exo $n_{\mathrm{O}} \rightarrow \sigma^{*}{ }_{\text {C-O }}$ interactions but it is important to point out that the hydrogen atom of the hydroxyl group points toward the center of the ring, position that produces stabilization due to the fact that it allows the interaction of one of the unshared electron pairs of the oxygen atom with the $\mathrm{C}-\mathrm{O}$ antibond.

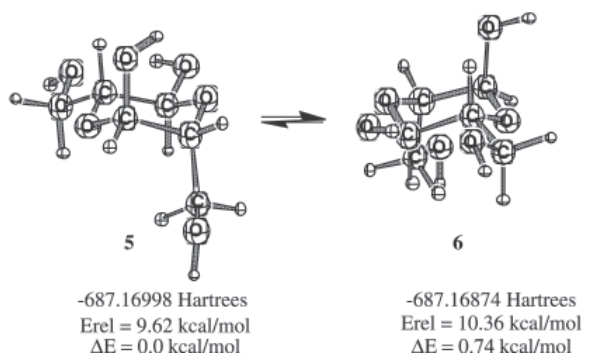

Conformer 6 maintains all the interactions shown by 5, except for the hydrogen atom of the axial hydroxyl group which is gauche in relation to the $\mathrm{C}-\mathrm{O}$ bond pointing to the outside of the ring. This shows that the hydrogen atom of conformer 5 provokes a stabilizing effect of 0.74 $\mathrm{kcal} / \mathrm{mol}$ compared to conformer $\mathbf{6}$.

To properly evaluate the effect of the hydrogen bondtype, several dispositions of these were evaluated in different conformers of the SRRR diasteroisomer (equation 4).

On the series of conformers $\mathbf{7}$ to $\mathbf{1 0}$, the axial hydroxyl group at position 2 maintains the hydrogen atom pointing towards the center of the ring and favoring two of the endo and exo-anomeric interactions. On conformer 11 the $\mathrm{O}-\mathrm{H}$ bond was placed in gauge position in relation to the $\mathrm{O}-\mathrm{C} 2$ bond, maintaining the same disposition of the other substituents. The fact that this conformer is at $0.89 \mathrm{kcal} /$ mol over conformer 10, confirms the stabilizing nature of the $\mathrm{OH}$ orientation towards the center of the ring.

On conformer 10, the most stable of the series of conformers shown in equation 4 , the hydroxyl group at position 5 also stays in axial position and participates in the formation of two hydrogen bonds. It is an acceptor in relation to the hydroxymethyl group at position 3 and is a donor in relation to the hydroxymethyl group at position 6. In this disposition, the $\mathrm{O}-\mathrm{H}$ bond is antiperiplanar to the C5-O bond, so if it participates in the $\sigma_{\mathrm{H}-\mathrm{O}} \rightarrow \sigma^{*}{ }_{\mathrm{C}-\mathrm{O}}$ stereoelectronic interaction, the resonance hybrid would 

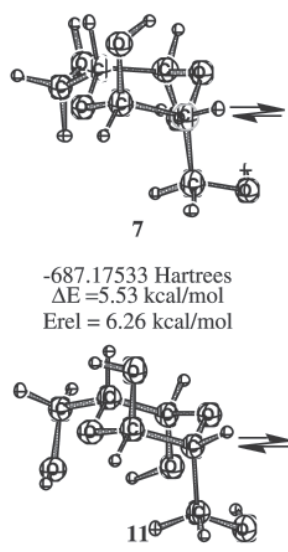

-687.18273 Hartrees $\Delta \mathrm{E}=1.6 \mathrm{kcal} / \mathrm{mol}$ Erel $=0.89 \mathrm{kcal} / \mathrm{mol}$
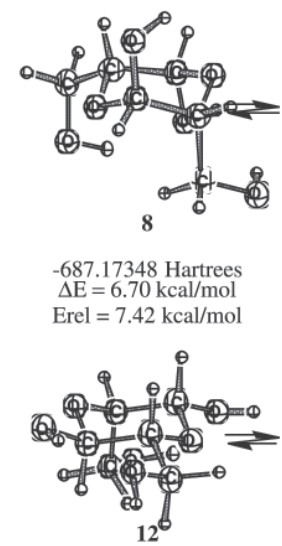

-687.17187 Hartrees $\Delta \mathrm{E}=7.71 \mathrm{kcal} / \mathrm{mol}$ $\begin{aligned} \Delta \mathrm{E} & =7.71 \mathrm{kcal} / \mathrm{mol} \\ & =8.43 \mathrm{kcal} / \mathrm{mol}\end{aligned}$

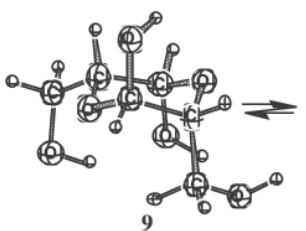

9

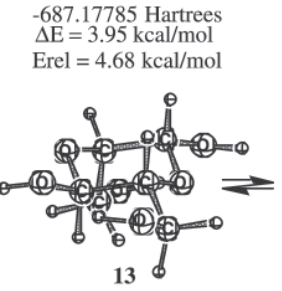

-687.17654 Hartrees $\Delta \mathrm{E}=4.78 \mathrm{kcal} / \mathrm{mol}$ $\Delta \mathrm{E}=4.78 \mathrm{kcal} / \mathrm{mol}$
$\mathrm{Ecal} / \mathrm{mol}$

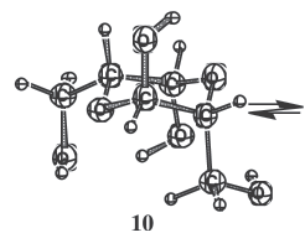

10

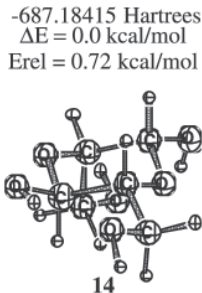

-687.17290 Hartrees $\Delta \mathrm{E}=7.06 \mathrm{kcal} / \mathrm{mol}$ $\mathrm{Erel}=7.79 \mathrm{kcal} / \mathrm{mol}$ make the hydrogen atom a better donor in the hydrogen bond and the oxygen would be a better acceptor. The stereoelectronic interaction would increase the tendency for the hydrogen bond formation. On conformer 9 the disposition of the unshared electron pairs is altered maintaining the hydroxyl group at position 5 as a participant of both bonds, but eliminating the stereoelectronic interactions as factors that accentuate the acidity of the proton in question. The energy increases $3.95 \mathrm{kcal} / \mathrm{mol}$ in relation to $\mathbf{1 0}$. On conformer $\mathbf{8}$ where the anomeric hydroxyl at position 5 is acceptor of both hydrogen bonds formed with the hydroxymethyl groups, the energy is increased $6.70 \mathrm{kcal} / \mathrm{mol}$. In conformer 7 , where one of the hydrogen bonds is broken by the rotation of the hydroxymethyl group only one bonds is maintained increasing the donor capacity of the C5 hydroxyl through the $\sigma_{\mathrm{H}-\mathrm{O}} \rightarrow \sigma^{*}{ }_{\mathrm{C}-\mathrm{O}}$ interaction. This produces an increase of $5.53 \mathrm{kcal} / \mathrm{mol}$ in relation to conformer $\mathbf{1 0}$.

On the series of conformers 12-14 the hydroxyl groups adopt the equatorial conformation losing the stabilization given by the endo-anomeric effect. Conformer $\mathbf{1 2}$ is 2.93 $\mathrm{kcal} / \mathrm{mol}$ less stable than conformer 13. These two conformers only differ in the fact that in $\mathbf{1 2}$ the hydroxyl group at position 2 is the donor of the hydrogen bond while in $\mathbf{1 3}$ it is the acceptor. The electronic arrangement on 13 allows the participation of the $n_{\text {Oexo }} \rightarrow \sigma^{*}{ }_{\text {C-O }}$ effect. In conformer 14 the $n_{\mathrm{O}} \rightarrow \sigma^{*}{ }_{\mathrm{C}-\mathrm{O}}$ stereoelectronic interaction is blocked just as on $\mathbf{1 2}$ but the change of the donor group of the hydrogen bond between the groups at positions 5 and 6 does not substantially affect the exo-anomeric interaction by allowing the disposition of one unshared electron pair in antiperiplanar arrangement to the $\mathrm{C} 5-\mathrm{O}$ bond.

The four diasteroisomers that, in addition to those presented before, are formed when a racemic mixture of the glyceraldehydes is studied (in addition to their corresponding enantiomers) are shown in equations 5 to 8 .

The diasteroisomer of configuration RRRS-2 and some of its conformers are presented in equation 5. The most stable conformer (16) allows the exo-anomeric interaction of the hydroxyl at position 2 that is the acceptor of the hydrogen bond that forms with the hydroxymethyl group at position 3. This is the most stabilizing arrangement of the hydrogen bond according to the observation on the SRRR-2 diasteroisomer. The hydroxyl group at position 5 shows an anomeric effect with the stabilizing arrangement where the hydrogen atom points toward the center of the ring just as it was shown for conformers $\mathbf{7}$ to $\mathbf{1 0}$ (equation 4). Curiously, the hydroxymethyl group at position 6 is isolated. Conformer 17 is at $0.70 \mathrm{kcal} / \mathrm{mol}$ in relation to 16. Here the equatorial hydroxyl group at $\mathrm{C} 2$ is the acceptor of the hydrogen bond. The endo- and exo-anomeric effect experienced by the $\mathrm{O}-\mathrm{H}$ at position 2 and the exo-anomeric
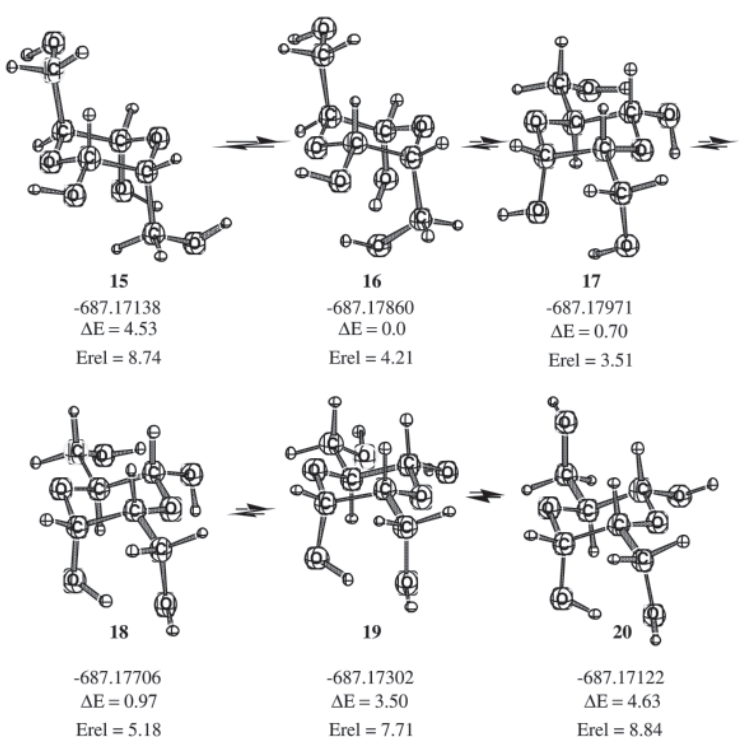
at position 5 should contribute importantly to its stabilization.

On conformer 15 several stabilizing interactions are destroyed. The hydroxyl at C5 forms the only hydrogen bond of the system with hydroxymethyl group at C3 and energy increases $4.53 \mathrm{kcal} / \mathrm{mol}$ in relation to $\mathbf{1 6}$. On 18 the only change is the donor of the hydrogen bond on segment $\mathrm{C} 2-\mathrm{C} 3$ of the ring in relation to $\mathbf{1 7}$ and the energy is slightly increased. This is different from what was observed in equation 2. The change of donor of the hydrogen bond between the substituents at positions 5 and 6 increases the energy in $2.53 \mathrm{kcal} / \mathrm{mol}$ of $\mathbf{1 9}$ in relation to $\mathbf{1 8}$. On this case, one of the unshared electron pairs of the oxygen atom is substituted by the $\mathrm{O}-\mathrm{H}$ bond. The $n_{\text {Oexo }} \rightarrow \sigma^{*}{ }_{\text {C-O }}$ interaction is more efficient than $\sigma_{\mathrm{H}-\mathrm{C}} \rightarrow \sigma^{*}{ }_{\mathrm{C}-\mathrm{O}}$, and originates, at least in part the observed destabilization. Finally, the rotation of the hydroxymethyl group on conformer 20 provokes the loss of the hydrogen bond with the recovery of the $n_{\text {Oexo }} \rightarrow \sigma^{*}{ }_{\text {C-O }}$ interaction. This increases the energy by $4.63 \mathrm{kcal} / \mathrm{mol}$ in relation to $\mathbf{1 6}$, but only by $1.13 \mathrm{kcal} / \mathrm{mol}$ in relation to $\mathbf{1 9}$, because it loses the hydrogen bond, but recovers the stereoelectronic interaction.

Three of the conformers of diasteroisomer RRSS-2 are shown on equation 6 . The most stable (23) presents both hydroxyl groups in axial position participating in the formation of hydrogen bonds. Diasteroisomer 22 is at 0.52 $\mathrm{kcal} / \mathrm{mol}$ and differs in relation to $\mathbf{2 3}$ in the fact that both anomeric hydroxyls are donors of hydrogen bonds attenuating the exo-anomeric interaction by substituting it by an interaction where the donor is the $\mathrm{O}-\mathrm{H}$ bond. Conformer 21 is at $3.35 \mathrm{kcal} / \mathrm{mol}$ in relation to $\mathbf{2 3}$, because it has lost the anomeric interactions and the hydroxyls that maintain the hydrogen bonds with the hydroxymethyl groups do not participate in the exo-anomeric effect.

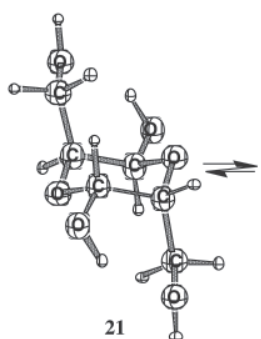

-687.17060 Hartress $\Delta \mathrm{E}=3.35 \mathrm{kcal} / \mathrm{mol}$ Erel $=9.23 \mathrm{kcal} / \mathrm{mol}$

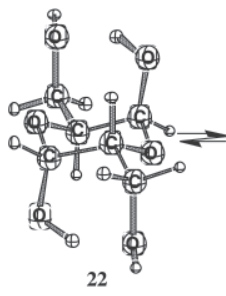

-687.17511 Hartress $\Delta \mathrm{E}=0.52 \mathrm{kcal} / \mathrm{mo}$ Erel $=6.40 \mathrm{kcal} / \mathrm{mol}$

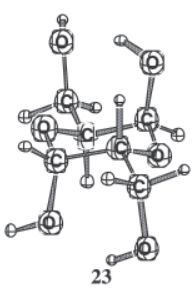

-687.17595 Hartress $\Delta \mathrm{E}=0.0 \mathrm{kcal} / \mathrm{mol}$ Erel $=5.87 \mathrm{kcal} / \mathrm{mol}$
The SRRS-2 diasteroisomer $\mathbf{2 4}$ (equation 7) is the most stable of all the molecules studied here, and it is, of course, the one where all interactions are constructive. This case shows, again, the additivity of stereoelectronic interactions. ${ }^{14}$ On this conformer the hydroxyl groups at anomeric positions are benefited from the endo and exoanomeric interactions. Also, they participate as donors of hydrogen bonds with the hydroxymethyl groups at positions 3 and 6 that are too hydrogen bond donors with endocyclic oxygen atoms. The change in the donating hydroxyl on conformer $\mathbf{2 5}$ causes the loss of the hydrogen bond with the oxygen atom that forms part of the ring causing an increase of almost $10 \mathrm{kcal} / \mathrm{mol}$. On conformer 26 (equation 7) the loss of stability originated by the anomeric effect causes an energy increase of $8.03 \mathrm{kcal} /$ mol even when the two hydrogen bonds where the anomeric hydroxyl is the donor are preserved.

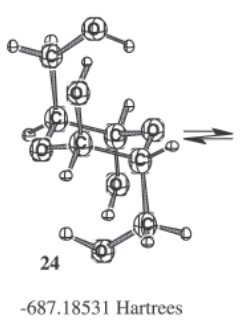

Erel $=0.0 \mathrm{kcal} / \mathrm{mol}$

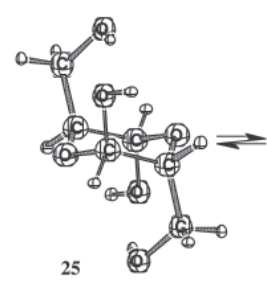

-687.16957 Hartrees Erel $=9.87 \mathrm{kcal} / \mathrm{mol}$

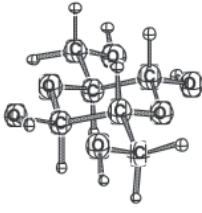

26

-687.17251 Hartrees Erel $=8.03 \mathrm{kcal} / \mathrm{mol}$
Finally, the diasteroisomer with SRSS-2 configuration (equation 8) was analyzed. The most stable conformer of the series has the axial hydroxyl in possibility to stabilize the molecule with the participation of the $n_{\text {Oendo }} \rightarrow \sigma^{*}{ }_{\text {C-O }}$ and $n_{\text {Oexo }} \rightarrow \sigma^{*}{ }_{\text {C-O }}$ interactions. In addition, it forms an hydrogen bond with the hydroxymethyl at position 6 . The hydroxyl at position 2 can participate in the $\sigma_{\mathrm{H}-\mathrm{O}} \rightarrow \sigma^{*}{ }_{\mathrm{C}-\mathrm{O}}$ interaction because the hydrogen atom participates in the formation of an hydrogen bond with the hydroxyl group at position 2 . The system where the donor of the hydrogen bond in segment C5-C6 changes (30) is located at 2.94 $\mathrm{kcal} / \mathrm{mol}$ in relation to 31 . Now the exo-anomeric interaction is lost. If this new hydrogen bond is maintained and the donor atom is modified in the segment C2-C3, conformer 29 is reached. Now, the C2 hydroxyl can participate in the $n_{\text {Oexo }} \rightarrow \sigma^{*}{ }_{\text {C-O }}$ interaction, but the energy increases $7.79 \mathrm{kcal} / \mathrm{mol}$ in relation to $\mathbf{3 1}$. Conformers 27 and 28 show substituents C2 and C3 in trans-diaxial position allowing the hydroxyl at position 2 of conformer 27 to benefit from $n_{\text {Oendo }} \rightarrow \sigma^{*}{ }_{\text {C-O }}$ and $n_{\text {Oexo }} \rightarrow \sigma^{*}{ }_{\text {C-O }}$ interactions in addition to forming a hydrogen bond as donor with the hydroxymethyl group at position 6. This hinders the stabilization of the system by hydroxyl group at C5 with hydrogen bond-type interactions and substantially increases the energy. On conformer $\mathbf{2 8}$ the change of donor atom of the C2-C6 hydrogen bond causes the loss of the $n_{\text {Oexo }} \rightarrow \sigma^{*}{ }_{\text {C-O }}$ interaction leading to an energy increase of $10.79 \mathrm{kcal} / \mathrm{mol}$ in relation to $\mathbf{3 1}$. 

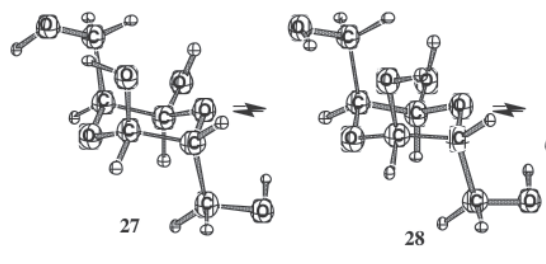

$-687.17262 \mathrm{Hartrees}$ $\begin{aligned} \Delta \mathrm{E} & =1.38 \mathrm{kcal} / \mathrm{mol} \\ \mathrm{Erel} & =7.69 \mathrm{kcal} / \mathrm{mol}\end{aligned}$

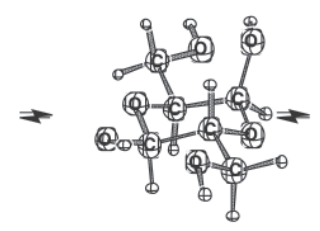

30

-687.17014 Hartrees $\Delta \mathrm{E}=2.94 \mathrm{kcal} / \mathrm{mol}$ Erel $=9.52 \mathrm{kcal} / \mathrm{mol}$

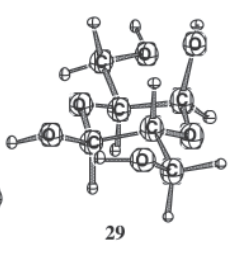

-687.17289 Hartrees $\begin{array}{rrr}-687.16812 \mathrm{Hartrees} & -687.17289 \mathrm{Hartrees} \\ \Delta \mathrm{E}=4.20 \mathrm{kcal} / \mathrm{mol} & \Delta \mathrm{E}=1.21 \mathrm{kcal} / \mathrm{mol} \\ \text { Erel }=10.79 \mathrm{kcal} / \mathrm{mol} & \mathrm{Erel}=7.79 \mathrm{kcal} / \mathrm{mol}\end{array}$ $\begin{array}{rrr}-687.16812 \mathrm{Hartrees} & -687.17289 \mathrm{Hartrees} \\ \Delta \mathrm{E}=4.20 \mathrm{kcal} / \mathrm{mol} & \Delta \mathrm{E}=1.21 \mathrm{kcal} / \mathrm{mol} \\ \text { Erel }=10.79 \mathrm{kcal} / \mathrm{mol} & \mathrm{Erel}=7.79 \mathrm{kcal} / \mathrm{mol}\end{array}$ Erel $=10.79 \mathrm{kcal} / \mathrm{mo}$
From the different conformers analyzed in their different conformations, it can be established that the compound with structure $\mathbf{2 4}$ is the compound determined by NMR due to its high symmetry presenting among other elements, a point of symmetry. In addition, it presents two types of hydrogen bonds just as determined by infrared analysis. The Erel value present in equations 1 to 8 refers to the energy of each isomer in relation to this all-axial compound. With exception of conformer $\mathbf{1 0}$ that is located at $0.73 \mathrm{kcal} / \mathrm{mol}$ over it, there are no possibilities of any other conformer participating in the equilibria from the population point of view.

Using $\mathrm{NBO}^{15}$ analysis, it is possible to determine the energy of both interactions, $n_{\text {Oexo }} \rightarrow \sigma_{\text {C-O }}^{*}$ and $n_{\text {Oendo }} \rightarrow$ $\sigma^{*}{ }_{\text {C-O }}$. The deletion energy of $\mathbf{2 4}$ establishes that the endoanomeric interaction is of $28.3 \mathrm{kcal} / \mathrm{mol}$, while the exoanomeric is of $30.2 \mathrm{kcal} / \mathrm{mol}$. However, these energies are dependent of the global disposition of the substituents since the $n_{\text {Oendo }} \rightarrow \sigma_{\text {C-O }}^{*}$ interaction on isomer $\mathbf{1 0}$ is only $2.1 \mathrm{kcal} / \mathrm{mol}$. This discrepancy led us to perform a systematic analysis of a series of conformers to evaluate the effect of the substituents. Thus, the series of compounds with SRSS configuration was evaluated. On conformer 27 the endo-anomeric interaction of the hydroxyl group on position 2 is of $3.02 \mathrm{kcal} / \mathrm{mol}$ while the exo-anomeric is of $27.4 \mathrm{kcal} / \mathrm{mol}$. On conformer 28 the endo-anomeric interaction is produced with $36.3 \mathrm{kcal} / \mathrm{mol}$, but since the antiperiplanar position is occupied by the $\mathrm{O}-\mathrm{H}$ bond since this group is acceptor of the hydrogen bond, the $\sigma_{\mathrm{H}-\mathrm{O}} \rightarrow$ $\sigma^{*}{ }_{\text {C-O }}$ interaction participates with $31.2 \mathrm{kcal} / \mathrm{mol}$. This is in contrast with the expected result since the donor capacity of the O-H should be smaller than that of an unshared electron pair. On compound 29 the endoanomeric interaction for the hydroxyl at position 5 is only $5.8 \mathrm{kcal} / \mathrm{mol}$ but the $\sigma_{\mathrm{H}-\mathrm{O}} \rightarrow \sigma^{*}{ }_{\mathrm{C}-\mathrm{O}}$ interaction is of 21.6 $\mathrm{kcal} / \mathrm{mol}$. For conformer 30 the endo-anomeric and $\sigma_{\mathrm{H}-\mathrm{O}}$ $\rightarrow \sigma^{*}{ }_{\mathrm{C}-\mathrm{O}}$ interactions are of 22.7 and $23.3 \mathrm{kcal} / \mathrm{mol}$, respectively and for conformer $\mathbf{3 1}$ they are of 26.0 and $28.7 \mathrm{kcal} / \mathrm{mol}$, respectively. These values show the importance of these interactions. ${ }^{16,17}$

On the other hand, according to Bader, ${ }^{18}$ the existence of a bond critical point and the bond trajectory that connects this critical point with two nuclear attractors are a necessary and sufficient conditions for a bond to exist. From the point of view of molecular structure, only demonstrating its existence, it is possible to satisfactorily prove the presence of a hydrogen bond. The molecular scheme of conformers $\mathbf{2 4}$ and $\mathbf{1 0}$ is shown on Figure 2.

For 24, the existence of 24 nuclear attractors, 28 bond critical points, 7 ring critical points and 2 cage critical points satisfy the Poincaré-Hopf relationship. ${ }^{19,20}$ Due to the symmetry, Table 1 only shows the critical points in the electronic density of the $\beta$ molecular region. As it can be observed, the value of the laplacians associated to the bond critical points of the hydrogen are positive which is typical of weak bonds.
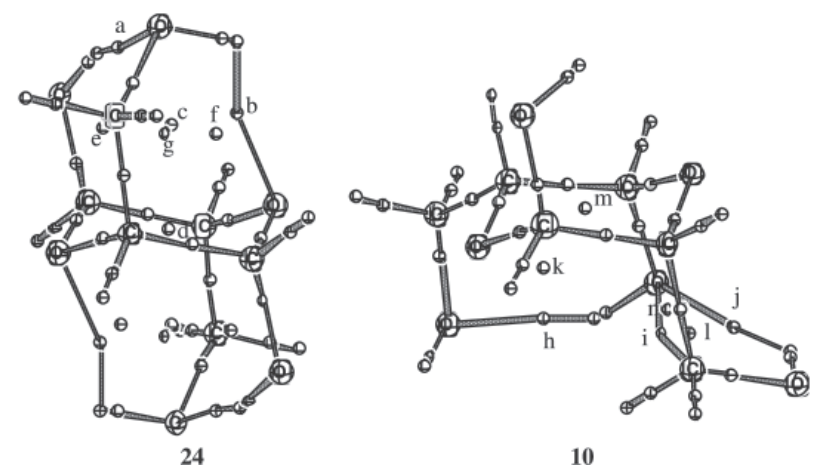

Figure 2. Critical Points associated with hydrogen bonds in conformers 10 and 24. See Table 1.

In addition, the weak bonds are curved so for a bond where the critical point corresponds to letter a (Figure 2), the bond trajectory is of 3.424 a.u. While the geometric distance that separates both nuclei is of $3.408(\mathrm{r}=1.554$ a.u.). For the second weak bond, the bond trajectory is of 6.306 a.u., while the geometric distance of the two nuclei joined by the bond is of 1.740 a.u. The stronger bond correspond to the one that closes the seven-membered ring where the hydroxyl in anomeric position is the donor while the weakest bond corresponds to that where the hydroxymethyl group is the donor and the oxygen atom that forms part of the 1,4-dioxane ring is the acceptor.

The second most stable isomer is at $0.73 \mathrm{kcal} / \mathrm{mol}$ over the one previously described. The analysis of the molecular structure is presented on Figure 2 and Table 1. Again, the importance of hydrogen bonds on molecular 
Table 1. Critical points related to weak interaction in compounds $\mathbf{2 4}$ and $\mathbf{1 0}$ (in au).

\begin{tabular}{|c|c|c|c|c|c|c|c|}
\hline cpd & signature & $\rho \times 10^{2}$ & $\nabla^{2} \rho \times 10^{2}$ & $\lambda^{\mathrm{a}} \times 10^{2}$ & $\lambda^{\mathrm{a}} \times 10^{3}$ & $\lambda^{\mathrm{a}} \times 10^{3}$ & $\varepsilon \times 10^{2}$ \\
\hline $24-a$ & $3,-1$ & 3.68 & 11.0 & -5.60 & -5.50 & 2.21 & 1.89 \\
\hline $24-b$ & $3,-1$ & 1.22 & 4.27 & -0.99 & -0.76 & 6.02 & 30.54 \\
\hline 24-c & $3,+1$ & 0.65 & 3.12 & -0.19 & 1.24 & 2.09 & \\
\hline $24-d$ & $3,+1$ & 2.17 & 12.9 & -1.78 & 6.78 & 7.95 & \\
\hline 24-e & $3,+1$ & 0.97 & 5.00 & -0.66 & 2.60 & 3.06 & \\
\hline 24-f & $3,+1$ & 1.12 & 5.05 & -0.64 & 1.16 & 4.54 & \\
\hline $24-g$ & $3,+3$ & 0.65 & 3.37 & 0.25 & 1.26 & 1.86 & \\
\hline 10-h & $3,-1$ & 3.08 & 9.92 & -4.33 & -4.18 & -1.84 & 3.19 \\
\hline $10-i$ & $3,-1$ & 1.09 & 4.36 & -6.73 & -3.79 & 5.42 & 77.4 \\
\hline $10-j$ & $3,-1$ & 1.42 & 5.01 & -1.53 & -1.31 & 7.84 & 16.79 \\
\hline $10-\mathrm{k}$ & $3,+1$ & 1.61 & 8.40 & -1.38 & 3.71 & 6.07 & \\
\hline $10-1$ & $3,+1$ & 1.04 & 4.63 & -0.57 & 0.64 & 4.56 & \\
\hline $10-\mathrm{m}$ & $3,+1$ & 2.25 & 1.35 & -1.87 & 7.56 & 8.16 & \\
\hline $10-n$ & $3,+1$ & 1.05 & 5.05 & -0.57 & 0.71 & 4.86 & \\
\hline
\end{tabular}

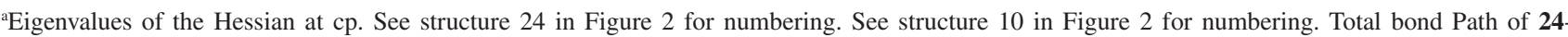
a: 3.424 au. Geometric bond length 3.408 au. difference: 1.554 au. total bond Path of 24-b: 6.306 au. Geometric bond length 4.566 au. difference: 1.74 au. total bond Path of 10-h: 3.593 au. Geometric bond length 3.564 au. difference: 0.027 au. Total bond Path of 10-i: 6.006 au. Geometric bond length 5.564 au. difference: 0.442 au. Total bond Path of 10-j: 4.345 au. Geometric bond length 4.238 au. difference: 0.107 au.

stability is evident. The set of the molecule is 24 nuclear attractors, 27 bond critical points, 4 ring critical points.

The hydrogen bonds identified by letters $h$ and $j(\mathbf{1 0})$ are normal and when the ring is closed, the corresponding critical points are produced. However, in electronic density it is possible to find an unexpected interaction between the oxygen atom at anomeric position 5 and the methylene group of the hydroxymethyl group at position 3. This interaction is expected for a 1,3-syn-diaxial interaction that was not possible to observe even in the axial methylcyclohexane. ${ }^{21}$

The energetic difference between conformer $\mathbf{2 4}$ of the SRRS diasteroisomer and conformer $\mathbf{1 0}$ of the diasteroisomer SRRR establishes that there is more than $99 \%$ of the former in relation to the latter and it is very possible that a minor group of signals observed in the spectrum is due to this isomer.

The calculations have been developed considering the different isolated conformers at $0 \mathrm{~K}$ and in vapor phase. In these conditions it would be expected that the interactions associated with the hydrogen bond would be exacerbated in a way where some of these interactions can be lost when the condensed phase is reached. It can also be expected that in solvents where the formation of hydrogen bonds is not important conformer $\mathbf{2 4}$ will predominate. However, when the solvent is capable of forming hydrogen bonds that compete with molecular interactions, then a substantial change in the properties of this equilibrium can be expected and the dominating structure may not be dominating anymore.

In a previous study we evaluated the capability of the BP/IGLOIII//B3LYP/6-31G(d,p) method to determine chemical shifts. ${ }^{22,23}$ We applied the same methodology to the most abundant conformers, and the results are shown in Figure 3.
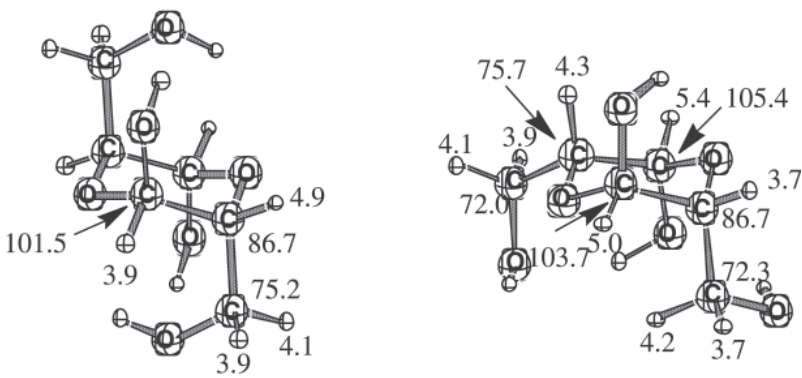

Figure 3. ${ }^{1} \mathrm{H}$ and ${ }^{13} \mathrm{C}$ chemical shifts with respecy to TMS of the global minima (isomer $\mathbf{2 4}$ on the left) and the conformer $\mathbf{1 0}$ (on the right) at BP/IGLOIII//B3LYP/6-31G(d,p) level of theory.

It is of primer importance to find out if the most abundant conformer descibed herein has a fundamental role in the composition of the equilibria determined by NMR. The absolute values of the ${ }^{13} \mathrm{C}$ chemical shift calculated and those determined experimentally shown a positive average difference of $10.5 \mathrm{ppm}$ for conformer 24 and of 9.9 ppm for conformer 10 , regarding the ${ }^{13} \mathrm{C}$ chemical shifts. Thus, both conformers can contribute to the ${ }^{13} \mathrm{C}$ NMR signals. In chloroform, it would be expected that the conformer 24 will be observed and when using polar solvents, these would compete with the formation of hydrogen bonds that produce important changes.

\section{Conclusions}

From the results presented here, it can be concluded that stabilizing effects, the stereoelectronic and the hydrogen bonds are additive. The most stable species in 
both, molecules isolated in vapor phase and in solvents that block the formation of intermolecular hydrogen bonds, will be the one that presents the most stabilizing effects. In this case, the most stable species is the 2S,5R-dihydroxy3R,6S-dihydroxymethyl-1,4-dioxane (24) conformer with all groups in axial position where four hydrogen bonds can be formed. A second observable conformer (10) is at $0.75 \mathrm{kcal} / \mathrm{mol}$ over the first one. The rest of the conformers have higher energies. NBO analysis established the importance of stereoelectronic interactions and with critical point analysis of electronic density the nature of the involved hydrogen bonds can be established.

\section{Experimental}

Samples of DL-Glyceraldehyde from a commerical supplier (Fluka) were used. It must be pointed out that DL-glyceraldehyde is crystaline and better than $97 \%$ pure while D-glyceraldehyde is usually sold as a syrup containing $85 \%$ of the compound and around $15 \%$ of water (this is the approximate composition of a monohydrate) apparently it has never been obtained in a crystalline form. However we managed to obtain a product with more than $97 \%$ D-glyceraldehyde and $2.7 \%$ of water. The reported purity of the sample by HPLC is $99.4 \%$. This sample showed an $[\alpha]_{\mathrm{D}}{ }^{20}$ value of $+14.92^{\circ}$ which after one minute turned to be +14.65 .

The infrared spectra of D-gluceraldehyde was obtained in a film over $\mathrm{NaCl}$ in a Bruker model tensor 27 spectrometer. The percent of free D-glyceraldehyde was calculated as $10 \% \pm 0.2 \%$ at $1724 \mathrm{~cm}^{-1}$ as described. ${ }^{7}$ The percent of free DL-glyceraldehyde was estimated by comparison of the integrated area of the carbonyl band in relation to the integrated bands at 2956, 2924 and 2855 $\mathrm{cm}^{-1}$ corresponding to $\mathrm{C}-\mathrm{H}$ strech vibration bands and then comparing this relation with that of the value corresponding to the relation between the integration of the carbonyl band of D-glyceraldehyde in relation with the integration in the region 2956 and $2855 \mathrm{~cm}^{-1}$ corresponding to $\mathrm{C}-\mathrm{H}$ bands. This comparison gave a value of $0.96 \%$ for the free aldehyde in the case of DL-glyceraldehyde. The ${ }^{1} \mathrm{H}$ and ${ }^{13} \mathrm{C}$ determinations were carried in a Varian Unity 300 instrument using perdeuterated dimethyl sulfoxide as solvent. In the case of DL-glyceraldehyde the protons at hydroxyl group at C-1 appears as a sharp doublet (6.720 and 6.697 ppm, two protons). In the case of the hydroxyl group at the hydroxymethylene chain the proton appears as a sharp triplet (centered at $4.558 \mathrm{ppm}$, two protons) both signals do not change appreciably between $20^{\circ} \mathrm{C}$ and $80{ }^{\circ} \mathrm{C}$. The samples were kept in a freezer at $-20{ }^{\circ} \mathrm{C}$ until used and were opened only to obtain the compounds just before running the spectroscopy.

\section{Computational methods}

Full geometry optimizations (no symmetry constraints) of all compounds were performed using the hybrid functional B3LYP with a 6-31G $(d, p)$ basis set. For all compounds six $d$ and $10 f$ orbital functions were used. These calculations were carried out with the Gaussian 94 Program (G94). ${ }^{24} \mathrm{NBO}$ analyses were performed with version 3.1 included in $\mathrm{G} 94,{ }^{25}$ and was used to evaluate changes in hyperconjugation. The interactions between filled and vacant orbitals represent the deviation of the molecule from the Lewis structure and can be used as a measure of delocalization. ${ }^{16,17}$ Wave functions were used to compute AIM atomic energies using the AIMPAC set of programs. $^{26}$

The ${ }^{1} \mathrm{H}$ and ${ }^{13} \mathrm{C}$ chemical shifts were calculated according to the proposed sum-over-states density functional perturbation theory (SOS-DFTPT) ${ }^{27}$ as implemented in a modified deMon-KS program. ${ }^{28}$ For the chemical shifts, the semilocal excange of Perdew and Wang $^{29}$ and the correlation functional by Perdew (PP) ${ }^{30}$ was used. This selection follows the suggestion made by the authors of SOS-DFTPT that this functional provides the best overall results for the simultaneous calculation of chemical shifts and spin-spin coupling constants. For the evaluation of the first-order corrections to the Kohn-Sham orbitals, the Local 1 approximation (LOC1) was used. The individual Gauge for Localized Orbitals (IGLO) was selected to approach the gauge problem, and the IGLO-III of Kutzelnigg et al. $^{31}$ was used as the basis set in the chemical shifts calculations. A fine grid with an extra iteration after achieving self-consistency was performed. Chemical shifts presented in this work are relative to tetramethyl silane (TMS).

\section{Acknowledgments}

We aknowledge to Isabel Chavez, Hector Ríos and María de las Nieves Zavala for the nuclear magnetic resonance determination. We are grateful to the Dirección General de Servicios de Cómputo Académico, Universidad Nacional Autónoma de México DGSCA, UNAM, to Consejo Nacional de Ciencia y Tecnología (CONACYT) for financial support via grant 40390-Q, to Dirección General de Asuntos del Personal Académico (DGAPA) via Grant No. IN-7200 and to Rebeca López García who revised the English version of this manuscript. 


\section{References}

1. Richard, M.; Krishna, N.I. In Biochemistry \& Molecular Biology of Plants; Buchanan, B.; Gruissem, W.; Jones, R., eds., 2000 American Society of Plant Physiologists: Rockville, Maryland, USA, Ch. 12, p.610-611.

2. Timberlake, K.C.; General Organic and Biological Chemistry; The Benjamin Cummings Publishing: San Francisco, CA, USA, 2002, Ch. 16

3. Juaristi, E.; Introduction to Stereochemistry and Conformational Analysis, Wiley: New York, 1994.

4. Wohl, A.; Ber. 1889, 31, 2394.

5. Wohl, A.; Neuberg, C.; Ber. 1900, 33, 3095.

6. Varonjan, Y. A.; Harty-Majors, S.; Ismail Ashraf, A.; Carboh. Res. 1999, 318, 20.

7. Swenson, C.A.; Barker, R.; Biochemistry 1971, 16, 3151.

8. Arreguin, B.; Taboada, J.; J. Crom. Sci. 1970, 8, 187.

9. Cram, D.J.; Abd Elhafez, F.A.; J. Am. Chem. Soc. 1952, 74, 5828.

10. Chapman, D.M.; Hester, R.E.; J. Phys. Chem. A. 1997, 101, 3382.

11. Martínez Mayorga, K.; Cortés, F.; Leal, I.; Reyna, V.; Quintana, D.; Antúnez, S.; Cuevas, G.; Arkivoc. 2003, XI, 132.

12. Juaristi, E.; Cuevas, G.; The Anomeric Effect, CRC press: Boca Raton, FL, 1994.

13. Juaristi, E.; Cuevas, G.; Tetrahedron, 1992, 48, 5019.

14. Cuevas, G.; Juaristi, E.; Vela, A.; J. Phys. Chem. A 1999, 103, 932; Cuevas, G.; Juaristi, E.; J. Am. Chem. Soc. 2002, 124, 13088; Martínez-Mayorga, K.; Juaristi, E.; Cuevas, G.; J. Org. Chem. 2004, 697266.

15. Alabugin, I. V.; Manoharan, M.; Peabody, S.; Weinhold, F.; J. Am.Chem. Soc. 2003, 125, 5973.

16. Cortés, F.; Tenorio, J.; Collera, O.; Cuevas, G.; J. Org. Chem. 2001, 66, 2918.

17. Cuevas, G.; Tenorio, J.; Cortés, F.; Rev. Soc. Quim. Méx. 2000, $44,42$.

18. Bader, R.F.W.; Atoms in Molecules, a Quantum Theory, Clerendon Press: Oxford, 1990; Bader, R.F.W. In Encyclopedia of Computational Chemistry; Schleyer, P.v.R., ed., 1998, John Wiley \& Sons: New York, p. 64.

19. Cuevas, G.; J. Am. Chem. Soc. 2000, 122, 692.

20. Madrid, G.; Rochín, A.; Juaristi, E.; Cuevas, G.; J. Org. Chem. 2001, 66, 2925.

21. Cortés-Guzmán, F.; Hernández-Trujillo, J.; Cuevas, G.; J. Phys. Chem. A. 2003, 44, 9253z.
22. Cuevas, G.; Juaristi, E.; Vela, A.; J. Mol. Struct. (Theochem) 1997, 418, 231.

23. Cortés, F.; Cuevas, G.; Tenorio, J.; Rochin, A.L.; Rev. Soc. Quim. Méx. 2000, 44, 7.

24. Gaussian 94, Revision D.4, Frisch, M. J.; Trucks, G.W.; Schlegel, H.B.; Gill, P.M.W.; Johnson, B.G.; Robb, M.A.; Cheeseman, J.R.; Keith, T.; Petersson, G.A.; Montgomery, J.A.; Raghavachari, K.; Al-Laham, M.A.; Zakrzewski, V.G.; Ortiz, J. V.; Foresman, J.B.; Cioslowski, J.; Stefanov, B.B.; Nanayakkara, A.; Challacombe, M.; Peng, C.Y.; Ayala, P.Y.; Chen, W.; Wong, M.W.; Andres, J.L.; Replogle, E.S.; Gomperts, R.; Martin, R.L.; Fox, D.J.; Binkley, J.S.; Defrees, D.J.; Baker, J.; Stewart, J.P.; Head-Gordon, M.; Gonzalez, C.; Pople, J.A., Gaussian, Inc.: Pittsburgh, PA, 1995.

25. NBO 3.1., Glendening, E. D.; Reed, A. D.; Carpenter, J. E.; Weinhold, F. Theoretical Chemistry Institute, University of Wisconsin: Madison, WI, 1993.

26. Biegler-Koing, F. W.; Bader, R. F. W.; Tang, T. H.; J. Comput. Chem. 1982, 3, 317.

27. Malkin, V.G.; Malkina, O.L.; Casida, M.E.; Salahub, D.R.; J. Am. Chem. Soc. 1994, 116, 5898; Malkin, V.G.; Malkina, O.L.; Eriksson, L.A.; Salahub, D.R. In Modern Density Functional Theory. A Tool for Chemistry; Seminario, J.M.; Politzer, P., eds., Elsevier: Amstardam, 1995.

28. St-Amant, A.; Salahub, D.R.; Chem. Phys. Lett. 1990, 169, 387; Salahub D.R.; Castro, M.E.; Proynov, E.I.; Relativistic and Electron Correlation Effects in Molecules and Solids, Vol. 318, of NATO ASI Series B: Physics, Plenum Press: New York, 1994, p. 411; Salahub, D.R.; Castro M.E.; Fournier, R.; Calaminici, P.; Godbout, N.; Goursot, A.; Jamorski, C.; Kobayashi, H.; Martinez, A.; Papai, I.; Proynov, E.; Russo, N.; Sirois, S.; Ushio, J.; Vela, A. In Theoretical and Computational Approaches to Interface Phenomena, Sellers, H.; Golab, J.T., eds., Plenum Press: New York, 1995, vol. 9, p. 187.

29. Perdew, J.P.; Wang, Y.; Phys. Rev. B 1986, 33, 8800.

30. Perdew, J.P.; Phys. Rev. B 1986, 33, 8822; ibid. 1986, 34, 7406.

31. Kultzelnigg, W.; Fleischer, U.; Schindler, M.; NMR-Basic Principles and Progress, Springer-Verlag: Heidelberg, vol. 33, 1990, p. 165.

Received: November 23, 2004 Published on the web: May 10, 2005 